Research Article

\title{
Evaluation of analgesic effect of tapentadol, a central novel analgesic versus tramadol, a widely used opioid analgesic in treatment of low back pain: a randomized controlled trial
}

\author{
Zaki Anwar Zaman*, Deepak Kumar
}

\begin{abstract}
Department of Pharmacology, Sri Krishna Medical College, Muzaffarpur, India
\end{abstract}

Received: 25 April 2013

Accepted: 10 May 2013

*Correspondence to:

Dr. Zaki Anwar Zaman,

Email:

zamanzakianwar@yahoo.co.in

(C) 2013 Zaman ZA et al. This is an open-access article distributed under the terms of the Creative Commons Attribution License, which permits unrestricted use, distribution, and reproduction in any medium, provided the original work is properly cited.

\begin{abstract}
Background: The objective of the study was to compare efficacy and tolerability (safety) of tapentadol with tramadol in the treatment of low back pain.

Methods: The study was a prospective, randomized, single blinded, total 102 patients are recruited for study in which 44 patients are prescribed (50mgtwice daily) tapentadol and 58 patients prescribed (50mg twice daily) tramadol for 4 weeks. Follow-up was done on days 7, 14, 28 and 4 week after stoppage of treatment. Assessment of improvement were performed by Indian Health Assessment Questionnaire Disability Index (Indian HAQDI), Visual Analogue Scale (VAS), Numerical Rating Scale (NRS) and measurement of Pain Relief Rate (PRR). Adverse events were recorded.

Results: Scores in Indian HAQDI, VAS and NRS improved significantly in both groups in the last visit but more so with tapentadol. PRR was reasonably higher with tapentadol [27( $n=44) 61.36 \%$ ] patients experiencing significant to complete pain relief at the end of the study, compared to tramadol $[25(n=58)$ $43.10 \%$ ]. Adverse effects was less in tapentadol group [15(n=44)34.09\%] versus 33( $\mathrm{n}=58) 56.89 \%$ ], $\mathrm{p}<0.05$ ].

Conclusion: Tapentadol has better sustained efficacy and tolerability than tramadol in low back pain.
\end{abstract}

Keywords: Tapentadol, Low back pain, Tramadol, Pain Relief Rate, Central novel analgesic

\section{INTRODUCTION}

The complex pathways of pain involve a number of mechanism situated at different sites within the C.N.S, with the spinal cord and brainstem playing key roles in the modulation of painful messages. ${ }^{1}$ There are both patient and animal data available to suggest that opioid controls may be reduced by neuropathy. ${ }^{2,3}$ Descending pathway controls, themselves originating and being controlled by limbic and cortical function, use the monoamines nor-adrenaline (NA) and 5hydroxytrytamine (5HT), which are heavily implicated in mood, sleep and fear. Preclinical data suggest that, whereas 5HT can both reduce and enhance pain, NA has a prominent inhibitory action, mediating through the activation of alpha2adrenaceptor. $^{4-6}$ These receptors are present in high density within superficial lamina of the dorsal horn, and are located on primary afferent terminals and postsynaptic dorsal horn cells alongside the opioid receptor. ${ }^{7,8}$ Alteration of noradrenaline inhibitory controls during pathological pain are well documented, indicating that an otherwise tonically active noradrenergic inhibition of spinal neurons is reduced after nerve injury.9-11 Activation of these inhibitory receptors reduces pain by inhibiting neurotransmitter release from primary afferent fibres and suppressing excitability of dorsal horn neurons. ${ }^{12,13}$ Tapentadol provides analgesia through two mechanism of action in a single molecules, MOR (Mu opioid receptor) agonist and NRI (nor-adrenaline reuptake inhibitor) mechanism. ${ }^{14}$

\section{METHODS}

Study design: The study was designed as a unicentric, prospective, single blind, randomized controlled trial with two parallel treatment arms.

Study procedure: Approval of protocol and study document was taken from institutional ethical committee before study commencement. After taken informed 
consent patients were screened for selection criteria. Screening and recruitment of patient were carried out at orthopaedic and medicine outpatient department of S.K. Medical College Hospital (Muzaffarpur) during the period October 2011-November 2012. Adult men and women within 40-65 years of age with low back pain of duration more than 6 weeks were recruited for the study.

Exclusion criteria: Patients suffering from significant disorder of kidney, liver, heart, thyroid, osteoporosis or malignancy were excluded. Patients taking NSAIDS, Corticosteroids or other related drugs were also excluded.

A total number of 102 patients were enrolled for the study. One group comprising of 44 patients received commercially available capsule of tapentadol $(50 \mathrm{mg}$ twice daily) and other group comprising of 58 patients received commercially available capsule of tramadol (50mg) twice daily after meal for 4 weeks. Subjects took the medication on their own at the scheduled time points. A trial diary was maintained by every patient.

Visits \& Follow up: The first visit (visit 0) was the one during which the patients was screened. It also serves as the baseline visit. The treatment was 4 weeks starting from date of selection and recruitment of individual patient. Every patient was contacted five times during the study. Visit 0, baseline visit on the day of recruitment, Visit-1 on day 7, Visit 2 on day 14, Visit 3 on day28 and Visit 4 was follow up visit 4 weeks after stoppage of treatment to know the after effect of the drugs. The total duration of study was of 8 weeks for the individual patients.

Clinical examination was performed and compliance was assessed by the "pill count" method at each follow-up assessment and at the end of the study. Adverse effect if any were also noted as per schedule Y. Bodyweight, height, baseline resting pulse rate and blood pressure were recorded on visit 0 . Laboratory test like complete blood count (CBC), fasting glucose, urea, creatinine, L.F.T, CRP were done at baseline and at the end of study.

Assessment of efficacy and tolerability: Disability index was scored for individual patient using a modified version of Indian Health Assessment Questionnaire. Patient's pain perception was noted on VAS scale which is $10 \mathrm{~cm}$ scale scored as ' 10 ' worst pain imaginable and ' 0 ' no pain and on an 11- point Numeral Rating Scale (NRS-11) with the end point " 0 "no pain and "10" worst pain imaginable. Pain Relief Rate (PRR), based on categorical transformation of degree of pain relief. " $<25 \%$ " unrelieved, " $25-49 \%$ " mere relief, " $50-74 \%$ " moderate relief, "75-99\%" significant relief, and "100\%" complete relief was also assessed. "VAS Score, NRS Score, HAQDI Score were assessed during each visit and PRR was assessed on visit 1, 2, 3 and 4.

In the end-of -trial visit (visit-4), 4 week after treatment completion, thorough clinical examination was done regarding the patient's pain relief and functional ability to assess the post-treatment effect of the drug. Physician's assessment of global efficacy and improvement of daily functional capacity was done on four point verbal rating scale (VRS-4) 0- No relief, 1- insufficient relief, 2satisfactory response, 3- excellent response, at the last visit. Safety and tolerability were also assessed at the end of the study.

Statistical analysis: Mean \pm standard deviation was used for description of data. Student's t test, Fisher's exact test and repeated measures ANOVA were employed in appropriate situations. A p-value of less than 0.05 was considered as statistically significant. SPSS $16^{\text {th }}$ version was used for statistical analysis.

\section{RESULTS}

Baseline characteristics of the group were identical (Table 1). The mean scores of VAS, NRS and Indian HAQ in four visits are shown in Figure $1 \& 2$. The group receiving tapentadol appeared to have comparable response to tramadol on visit-1 and visit-2. Sustained effect on visit-3 and visit-4 (four weeks after stoppage of drugs) was better in case of tapentadol as evidenced by better scores. The PRR measurement showed that number of patients experiencing significant to complete pain relief 4 week after discontinuation of treatment (i.e. in visit 4) was more in the tapentadol group $[27(\mathrm{n}=44) 61.36 \% \quad$ versus $\quad 25(\mathrm{n}=58) 43.10 \%] \quad \mathrm{P}<0.05$ [Table $2 \& 3$ ]. PRR measurement in other visits showed no significant difference. Physician assessment of global efficacy and improvement of daily functional capacity by VRS-4 also showed marginally greater number of patients experiencing satisfactory \& excellent response at the end of study [38( $n=44) 86.36 \%$ versus $34(n=58) 58.62 \%$ ] in the tapentadol group [Figure $3 \& 4$ ].

Table 1: Baseline characteristic of the study groups.

\begin{tabular}{|llll|}
\hline & $\begin{array}{l}\text { Tapentadol } \\
\text { group }(\mathrm{n}=44)\end{array}$ & $\begin{array}{l}\text { Tramadol } \\
\text { group } \\
(\mathrm{n}=58)\end{array}$ & $\begin{array}{l}\text { P } \\
\text { value }\end{array}$ \\
\hline Mean age & $52 \pm 4.64$ & $54 \pm 5.73$ & NS \\
\hline Male: Female & $20: 24$ & $28: 30$ & NS \\
\hline B.M.I $\left(\mathrm{kg} / \mathrm{m}^{2}\right)$ & $26 \pm 4$ & $25 \pm 3.4$ & NS \\
\hline $\begin{array}{l}\text { Duration } \\
\text { (weeks) }\end{array}$ & $12 \pm 4.62$ & $13 \pm 2.16$ & NS \\
\hline
\end{tabular}

Note- NS $=$ Not Significant, B.M.I= Body Mass Index

The tolerability of tapentadol appeared to be significantly superior to tramadol with less number of patients experiencing adverse drug reaction [15(n=44)34.09\% versus [33( $n=58) 56.89 \%$ ] [Figure 5]. 


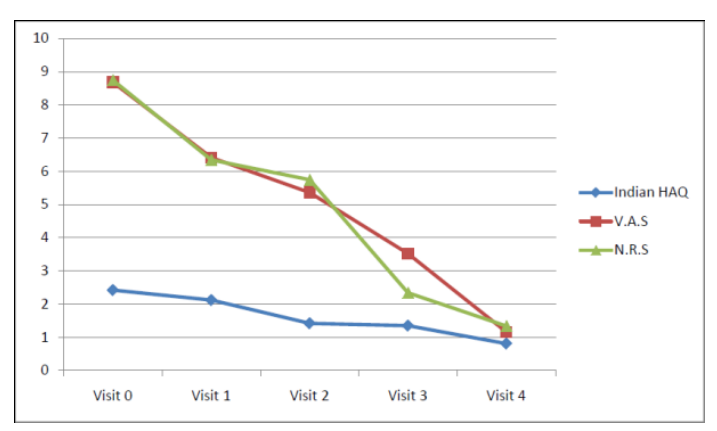

Figure 1: Assessment of improvement in tapentadol group.

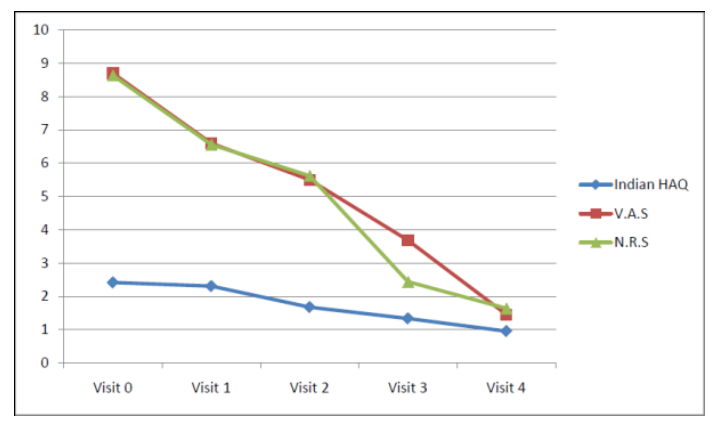

Figure 2: Assessment of improvement in tramadol group.

Table 2: Pain relief rates in tapentadol groups $(n=44)$ at different follow up.

\begin{tabular}{|lllll|}
\hline & $1^{\text {st }}$ visit & $2^{\text {nd }}$ visit & $3^{\text {rd }}$ visit & $4^{\text {th }}$ visit \\
\hline Unrelieved & $4(9.09)$ & $4(9.09)$ & $3(6.81)$ & $2(4.55)$ \\
\hline Mere relief & $11(25)$ & $10(22.72)$ & $6(13.63)$ & $3(6.81)$ \\
\hline $\begin{array}{l}\text { Moderate } \\
\text { relief }\end{array}$ & $21(47.72)$ & $20(45.45)$ & $13(29.54)$ & $12(27.27)$ \\
\hline $\begin{array}{l}\text { Significant } \\
\text { relief }\end{array}$ & $12 \pm 4.62$ & $8(18.18)$ & $17(38.64)$ & $19(43.18)$ \\
\hline $\begin{array}{l}\text { Complete } \\
\text { relief }\end{array}$ & $7(15.90)$ & $2(4.55)$ & $5(11.36)$ & $8(18.18)$ \\
\hline
\end{tabular}

Note: Numbers in brackets denote percentages of total number of patients in respective groups.

Table 3: Pain relief rates in tramadol groups $(n=58)$ at different follow up.

\begin{tabular}{|lllll|}
\hline & $1^{\text {st }}$ visit & $2^{\text {nd }}$ visit & $\mathbf{3}^{\text {rd }}$ visit & $\mathbf{4}^{\text {th }}$ visit \\
\hline Unrelieved & $4(6.89)$ & $5(8.62)$ & $2(3.45)$ & $2(3.45)$ \\
\hline Mere relief & $13(22.41)$ & $12(20.69)$ & $6(10.34)$ & $7(12.06)$ \\
\hline $\begin{array}{l}\text { Moderate } \\
\text { relief }\end{array}$ & $30(51.72)$ & $28(48.27)$ & $24(41.38)$ & $24(41.38)$ \\
\hline $\begin{array}{l}\text { Significant } \\
\text { relief }\end{array}$ & $9(15.52)$ & $11(18.96)$ & $20(34.48)$ & $19(32.76)$ \\
\hline $\begin{array}{l}\text { Complete } \\
\text { relief }\end{array}$ & $2(3.45)$ & $2(3.45)$ & $6(10.34)$ & $6(10.34)$ \\
\hline
\end{tabular}

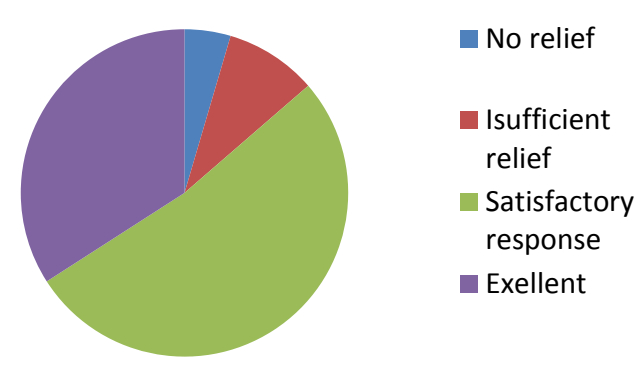

Figure 3: Global efficacy \& daily functional capacity improvement in tapentadol group.

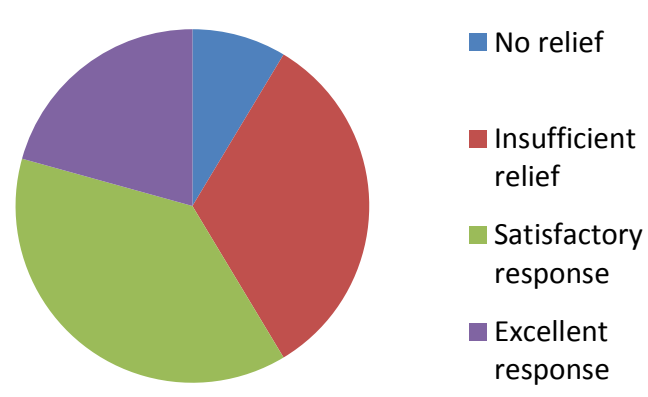

Figure 4: Global efficacy \& daily functional capacity improvement in tramadol group.

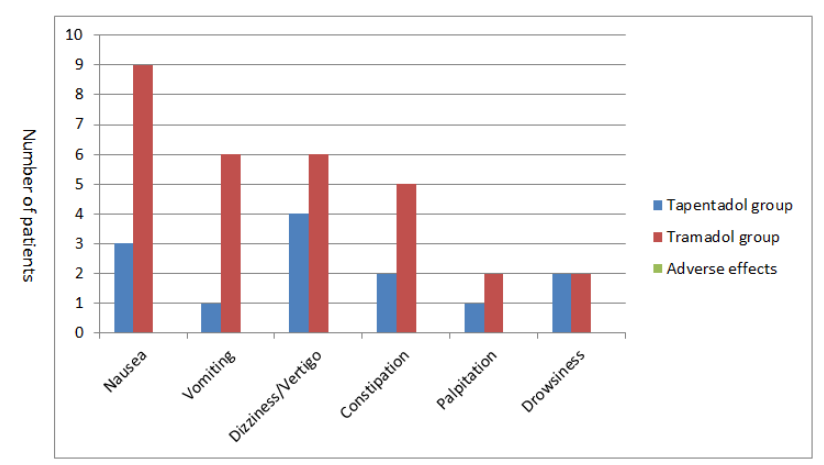

Figure 5: Bar diagram showing relative proportions of various adverse events occurring in the study population.

Figure 3 \& 4 pie diagram showing physicians' assessment of global efficacy and improvement of daily functional capacity on Verbal Rating Scale (VRS-4) Note- Areas denote percentages of total number of patients in respective groups.

\section{DISCUSSION}

Clinical trial studies indicate that tapentadol is an effective analgesic for a range of pain conditions with efficacy similar to comparison doses of either oxycodone or morphine but with lower incidences of adverse gastrointestinal events. ${ }^{15-17}$ The efficacy of tapentadol for the relief of moderate to severe acute pain was demonstrated in both in-patient and out-patient settings and in both visceral and somatic pain conditions such as 
bunionectomy (Daniels et al., 2009a; Daniels et al., 2009b; Stegmann et al., 2008)), ${ }^{18,19}$ end-stage degenerative knee or hip joint disease (Etropolski et al., 2011; Hale et al., 2009; Hartrick et al., 2009), ${ }^{20}$ and hysterectomy (Study KF5503/35). Tapentadol ER provided effective analgesia for patients with chronic osteoarthritis and low back pain (Afilalo et al., 2010; Etropolski et al., 2010; Lange et al., 2010) $)^{21-23}$ and pain associated with diabetic peripheral neuropathy (Schwartz et al., 2011; Steigerwald et al., 2012. ${ }^{24,25}$ Neuropathic pain states are often discussed in reviews of tapentadol's clinical efficacy with the hope that the two potentially synergistic mechanisms of opioid agonism and NRI will be an improvement for tapentadol over analgesics with just a single mechanism of action (Hartrick et al., 2012; Hoy, 2012; Pierce et al., 2012). ${ }^{26-28}$ Tapentadol was developed to combine agonist activity at the $\mu$ opioid receptor (MOR) with norepinephrine (NE) reuptake inhibition (NRI) for improved analgesic efficacy especially in chronic or neuropathic pain disorders. These two analgesic entities exist in a single nonracemic molecule without active metabolites which leaves the relative contributions of the different mechanisms steady over the course of metabolic transformation and purportedly reduce adverse effects. Currently, the adverse reactions in humans are predominantly reported in clinical trials (Daniels et al., 2009a; Hale et al., 2009; Hartrick et al., 2009; Jeong et al., 2012; Vorsanger et al., $2011 .^{29-32}$ In an analysis of the Phase II/III Multiple-dose Double-blind studies, the percentage of subjects with at least one treatment emergent adverse events (TEAE) was higher in the tapentadol group compared with the placebo group and was lower in the tapentadol group compared with the oxycodone group. The most commonly reported (by $\geq 5 \%$ of subjects) TEAEs in the tapentadol group were nausea, dizziness, vomiting, somnolence, headache, constipation and pruritus. The percentage of subjects with TEAEs relating to gastrointestinal disorders (nausea, vomiting and constipation) and with dizziness was lower in the tapentadol group compared with the oxycodone IR group and the percentage of subjects with somnolence or headache was similar between the two groups. Our study showed the superiority of tapentadol in sustaining pain relief 4 weeks after discontinuation of treatment compared to tramadol. The sustained improvement after discontinuation of therapy is evidenced by better pain relief rates in tapentadol group. Tapentadol also showed greater tolerability compared to tramadol. These data suggest that tapentadol can be used safely and effectively in patient with low back pain. It may be a better alternative to tramadol as regards tolerability and sustained effect.

\section{Funding: None}

Conflict of interests: None declared

Ethical approval: Approved by the Institutional Ethical Committee

\section{REFERENCES}

1. Dickenson, AH, KIeffer B. Opiates: basic mechanisms. In: Textbook of pain. McMahon SB, Koltzenburg M, eds. Elsevier, 2006: 427-42.

2. Portenoy RK, Foley KM, Inturrisi CE. Pain 1990;43:273-86.

3. Suzuki R, Chapman V, Dickenson AH. Pain 1999; 80:215-28.

4. Howe JR, Wang JY, Yaksh TL. J Pharmacol Exp Ther 1983;224:552-8.

5. Proudfit HK. Prog Brain Res 1988;77:357-70.

6. Yaksh TL. Pharmacol Biochem Behav1985;22:84558.

7. Nicholas AP, Pieribone V, Hokfelt T. J Comp Neurol 1993;328:575-94.

8. Shi TJ, Winzer-Serhan U, Leslie $F$, et al. Neuroreport 1999;10:2835-9.

9. Ren K, Ruda MA. Neuroreport 1996;7:2186-90.

10. Suzuki R, Morcuende S, Webber M, et al. Nat Neurosci 2002;5:1319-26.

11. Rahman W, D'Mello R, Dickenson AH. J Pain 2008;9:350-9.

12. Budai D, Harasawa I, Fields HL. J Neurophysiol 1998;80:2244-54.

13. Sullivan AF, Kalso EA, McQuay HJ, et al. Eur J Pharmacol 1992;215:127-33.

14. Christoph T, De Vry J, Tzschentke TM. Neurosci Lett 2010;470:91-4.

15. Jeong ID, Camilleri M, Shin A, Iturrino J, Boldingh A, Busciglio I, et al. A randomised, placebocontrolled trial comparing the effects of tapentadol and oxycodone on gastrointestinal and colonic transit in healthy humans. Aliment Pharmacol Ther 2012. doi: 10.1111/j.1365-2036.2012.05040.x.

16. Vadivelu N, Timchenko A, Huang Y, Sinatra R (2011). Tapentadol extended-release for treatment of chronic pain: a review. J Pain Res 4:211-8.

17. Wade WE, Spruill WJ (2009). Tapentadol hydrochloride: a centrally acting oral analgesic. Clin Ther 2009;31(12):2804-18.

18. Daniels SE, Upmalis D, Okamoto A, Lange C, Haeussler J. A randomized, double-blind, phase III study comparing multiple doses of tapentadol IR, oxycodone IR, and placebo for postoperative (bunionectomy) pain. Curr Med Res Opin 2009;25(3):765-76.

19. Stegmann JU, Weber H, Steup A, Okamoto A, Upmalis D, Daniels S (2008). The efficacy and tolerability of multiple-dose tapentadol immediate release for the relief of acute pain following orthopedic (bunionectomy) surgery. Curr Med Res Opin 24(11): 3185-3196.

20. Etropolski M, Kelly K, Okamoto A, Rauschkolb C (2011). Comparable efficacy and superior gastrointestinal tolerability (nausea, vomiting, constipation) of tapentadol compared with oxycodone hydrochloride. Adv Ther 28(5): 401-417.

21. Afilalo M, Etropolski MS, Kuperwasser B, Kelly K, Okamoto A, Van Hove I, et al. (2010). Efficacy and 
safety of Tapentadol extended release compared with oxycodone controlled release for the management of moderate to severe chronic pain related to osteoarthritis of the knee: a randomised double-blind, placebo- and active-controlled phase III study. Clin Drug Investig 30(8): 489-505.

22. Etropolski MS, Okamoto A, Shapiro DY, Rauschkolb C (2010). Dose conversion between tapentadol immediate and extended release for low back pain. Pain Physician 13(1): 61-70.

23. Lange B, Kuperwasser B, Okamoto A, Steup A, Haufel T, Ashworth J, et al. (2010). Efficacy and safety of tapentadol prolonged release for chronic osteoarthritis pain and low back pain. Adv Ther 27(6): 381-399.

24. Schwartz S, Etropolski M, Shapiro DY, Okamoto A, Lange R, Haeussler J, et al. (2011). Safety and efficacy of tapentadol ER in patients with painful diabetic peripheral neuropathy: results of a randomized-withdrawal, placebo-controlled trial. Curr Med Res Opin 27(1): 151-162.

25. Steigerwald I, Muller M, Davies A, Samper D, Sabatowski R, Baron R, et al. (2012). Effectiveness and Safety of Tapentadol Prolonged Release for Severe, Chronic Low Back Pain With or Without a Neuropathic Pain Component: Results of an Openlabel Phase 3b Study. Curr Med Res Opin.

26. Hartrick CT, Rodriguez Hernandez JR (2012). Tapentadol for pain: a treatment evaluation. Expert Opin Pharmacother 13(2): 283-286.

27. Hoy SM (2012). Tapentadol extended release: in adults with chronic pain. Drugs 72(3): 375-393.
28. Pierce DM, Shipstone E. Pharmacology Update: Tapentadol for Neuropathic Pain. Am J Hosp Palliat Care 2012;29:663-6.

29. Daniels S, Casson E, Stegmann JU, Oh C, Okamoto A, Rauschkolb C, et al. (2009a). A randomized, double-blind, placebo-controlled phase 3 study of the relative efficacy and tolerability of tapentadol IR and oxycodone IR for acute pain. Curr Med Res Opin 25(6): 1551-1561.

30. Hale M, Upmalis D, Okamoto A, Lange C, Rauschkolb C (2009). Tolerability of tapentadol immediate release in patients with lower back pain or osteoarthritis of the hip or knee over 90 days: a randomized, double-blind study. Curr Med Res Opin 25(5): 1095-1104.

31. Hartrick C, Van Hove I, Stegmann JU, Oh C, Upmalis D. Efficacy and tolerability of tapentadol immediate release and oxycodone $\mathrm{HCl}$ immediate release in patients awaiting primary joint replacement surgery for end-stage joint disease: a 10-day, phase III, randomized, double-blind, activeand placebo-controlled study. Clin Ther 2009;31(2): 260-271.

32. Vorsanger G, Xiang J, Okamoto A, Upmalis D, Moskovitz B. Evaluation of study discontinuations with tapentadol immediate release and oxycodone immediate release in patients with low back or osteoarthritis pain. J Opioid Manag 2010;6(3):16979.

doi:10.5455/2319-2003.ijbcp20130809

Cite this article as: Zaman ZA, Kumar D. Evaluation of analgesic effect of tapentadol, a central novel analgesic versus tramadol, a widely used opioid analgesic in treatment of low back pain: a randomized controlled trial. Int J Basic Clin Pharmacol 2013;2:392-6. 